\title{
Sociedade Civil e seu Papel Político: O Local e o Global como Espaços de Participação Cidadã
}

\author{
Elenaldo Celso Teixeira*
}

$P$ rocuramos sintetizar neste artigo $^{1}$ algumas conclusōes da análise realizada sobre o papel político da sociedade civil frente ao poder local, a partir das contribuições teóricas de Jean Cohen, Andrew Arato (1992) e Habermas (1997)). Os primeiros, em trabalho exaustivo de revisão de toda a literura sobre a teoria da sociedade civil e do debate em torno das mudanças políticas ocorridas na década de 80 , redefine e reconstrói o conceito, concebendo-o como movimento e como instituição, com ações coletivas desenvolvidas por uma pluralidade e heterogeneidade de atores no sentido da democratização da sociedade e do estado, do controle social do mercado. Arato (1995:27) acentua a necessidade de analisar os governos locais em termos de fortalecimento da sociedade civil. Habermas, (1997: 94) em seu último livro, retoma a discussão sobre esfera pública, relacionando-a com o conceito de sociedade civil, diferenciando-a do sistema (econômico e político), descrita como "rede adequada para comunicação de conteúdos, tomadas de posição e opiniões". Fundamentados nestas perspectivas teóricas, buscamos situar as observações de experiências e ações coletivas realizadas em vários países frente aos desafios colocados pelo processo de globalização, em que o local, por vários motivos, passa a ser valorizado enquanto espaço de inovações de gestão pública e de participação cidadã.

Os exemplos de ações coletivas observadas demonstram o exercício de uma lógica presidida por valores de solidariedade, respeito às diferenças, busca do convencimento racional, através do debate público das ques-

"Professor Adjunto do Departamento de Ciência Política, FFCH, UFBa. 
tões e de realização de projetos econômicos, educativos e comunicacionais, num processo de empowerment dos segmentos sociais marginalizados. Não obstante, não se pode minimizar as assimetrias existentes na sociedade quanto ao domínio das informações e recursos e das limitações cognitivas que dificultam a ação comunicativa; nem obscurecer a existência dos interesses que permeiam as ações dos grupos sociais nos embates nos espaços públicos. Buscamos, como sugere Habermas (1997), identificar, nas práticas sociais, fragmentos de uma "razão existente" e verificar como a categoria "sociedade civil", além de constituir-se num marco orientador importante para a ação política (Costa, 1997), pode desempenhar função analítica relevante, apesar das limitações que podem levar à superestimação do seu papel político e sua idealização, se não se leva em conta que é um conceito em reconstrução e que a realidade é bem mais complexa.

O conjunto dos elementos que constitui o que hoje se denomina "sociedade civil" - pluralidade de atores, publicidade, privacidade, legalidade - exige um suporte de institucionalidade com base nos direitos fundamentais que motivam as ações coletivas dos diversos atores, não apenas no sentido de circunscrevê-los a uma ordem jurídica estatal, mas de ampliálos pela construção de novos direitos. Em termos globais, o papel exercido pelas organizações da sociedade civil nas conferências internacionais do Sistema ONU tem sido relevante para tematizar e publicizar questões vividas no cotidiano pelas populações, criando assim uma esfera pública de caráter global. Através do debate público, das mobilizações sociais, as autoridades são impelidas a assumir compromissos e dar-lhes respostas mediante leis e políticas públicas, a exemplo dos direitos das mulheres, das crianças e adolescentes e da segurança alimentar, objeto em muitos países como o nosso, de legislaçóes específicas e programas governamentais. Trata-se, pois, de uma nova institucionalidade em que a sociedade civil, por meio dos setores sociais diretamente envolvidos, passa a fazer parte de sua construção, seja pelo atendimento objetivo das demandas, seja pela criação de canais permanentes de interlocução entre sociedade e Estado, como os conselhos de gestão, plataformas de ação, fóruns, constituindo assim, uma esfera pública, para além do Estado. No entanto, há áreas institucionais de decisões estratégicas até agora impenetráveis a qualquer influência de outra lógica que não a sistêmica, a exemplo das políticas macroeconômicas do Banco Mundial ou da OMC que geralmente orientam políticas nacio- 
Sociedade Civil e seu Papel Político: O Local e o Global como Espaços de Participação Cidadä

nais e, em termos locais, das decisões das elites tradicionais. Nesse processo de interlocução sociedade/estado há o risco da burocratização de procedimentos, da cooptação de atores sociais, mas, de alguma forma contornado por outros tipos de ação coletiva desenvolvidos paralelamente pelas organizações em espaços públicos autônomos. A própria organização autônoma da sociedade civil cria espaços públicos abertos, propensos à rediscussão das questões e ao controle social do poder público. Em termos nacionais e locais, os exemplos referidos em relação ao Brasil e a alguns países do Terceiro Mundo demonstram as possibilidades criadas com essa institucionalidade e, ao mesmo tempo, suas limitações concretas em função da cultura política vigente e da impermeabilidade das estruturas político-sociais desses países.

O papel da sociedade civil em relação ao Estado e ao mercado, na visão que adotamos, é concebido como autolimitado, no sentido de não substituir a função dessas estruturas, mas de exercer influência sobre suas decisões e políticas. Nessa ótica, tal influência não é apenas exercida na escolha dos decisores, através de eleições periódicas, mas também na proposição de parâmetros para decisão. As experiências analisadas indicam um papel permanente da sociedade civil face ao Estado, em vários países, seja através dos mecanismos institucionais criados ou instrumentos legais disponíveis aos cidadãos, seja por meio da pressão social e da ação direta. A sociedade civil não assume poderes de decisão ou gestão, criando estruturas paralelas, nem exerce apenas uma ação periódica (eleições) ou episódica (referendo, plebiscito). O papel da sociedade civil é realizado em dois planos: um - ofensivo - relacionado com o Estado e o mercado, constituído dos diversos tipos de ação coletiva; o outro, de caráter "defensivo", buscando ... preservar certas estruturas da associação e da esfera pública, produzir contra-esferas públicas subculturais e contra-instituições, solidificar identidades coletivas e ganhar novos espaços na forma de direitos mais amplos $e$ instituiçöes reformadas (Cohen e Arato, apud Habermas, 1997, p. 103).

Observa-se o exercício incipiente desse duplo papel, principalmente em relação ao Estado: ações coletivas voltadas para a formação de opinião e para pressão sobre órgãos decisores, visando à adoção de determinadas políticas nos espaços global, nacional e local; em termos defensivos, a criação de redes internacionais ou nacionais, a realização de projetos de cooperação, capacitação, encontros e congressos para debate dos problemas 
comuns tendo em vista o fortalecimento da própria sociedade civil. Quanto ao mercado, os exemplos analisados são ainda escassos, a não ser no aspecto defensivo: redes de "comércio justo" na Europa, cooperativas de pequenos produtores e sistemas de créditos alternativos, defesa do consumidor, etc. O papel ofensivo nesse campo é ainda muito limitado. Por exemplo, a discussão sobre regras relativas à atuação do capital financeiro e sua responsabilização pelos efeitos no empobrecimento dos países do Terceiro Mundo e no meio ambiente é ainda restrita a algumas organizações internacionais do sistema ONU, e às diversas Conferências Internacionais, apesar da crescente atuação de organizações voltadas para o acompanhamento e questionamento das políticas financeiras globais, a exemplo da Rede Brasil sobre Instituições Financeiras Multilaterais. Inexistem porém, canais institucionais para uma interlocução permanente entre sociedade civil e organismos multilaterais, apesar de algumas iniciativas em andamento como o GTONG.- Grupo de Trabalho de ONGs junto ao Banco Mundial e outras entidades internacionais, o Painel de Inspeção do Banco Mundial, etc.

Não obstante, percebemos também uma ação cada vez mais forte de alguns tipos de organização no espaço internacional, visualizando a perspectiva de uma "sociedade civil global". Através da participação nas Conferências Oficiais internacionais, principalmente nas temáticas sociais e culturais, as organizações da sociedade civil, hoje atuam como delegados, com direito à voz ou através de Fóruns Alternativos, paralelos às Conferências, discutindo temáticas e questões cruciais, propondo alternativas e diretrizes. Realizam também ações coletivas de mobilização e de protestos contra as políticas globais, principalmente as de natureza econômico-financeira, sem maiores impactos a não ser a publicização de posições e a denúncia dos efeitos perversos da aplicação dessas políticas.

As experiências analisadas refletem pois a insuficiência do exercício do papel político da sociedade civil. Consideramos que os agentes do poder público não devem transferir as próprias responsabilidades para as organizaçōes da sociedade civil pois recebem um mandato para exercê-las e devem ser cobrados por isso. Cabe à sociedade civil, sim, o papel de controle social sobre o Estado, em dois sentidos : - o de accountability, envolvendo a transparência das decisões e a prestação de contas e o de responsabilização dos agentes pelos atos e políticas adotadas. 
Sociedade Civil e seu Papel Político: O Local e o Global como Espaços de Participação Cidadã

Em relação ao controle social do poder político, iniciativas de êxito têm sido promovidas em alguns países (controle da apuração de votos no México; controle da corrupção na Coréia; Observatório de Cidadaniaavaliação dos compromissos assumidos nas conferências internacionais). No entanto, tratando-se de proposições de mecanismos de aperfeiçoamento do sistema representativo, de combate à ineficiência do Estado, são poucas as experiências até porque, em termos teóricos pouco se avançou nessa questão ( Bobbio, 1986; Przeworski, 1998). A questão vital para a avaliação dos mandatos de representantes políticos como a accountability $e$ a consequente reponsabilização política e penal não mereceu ainda a atenção devida das organizaçōes, considerando que se trata de um problema crucial para que a sociedade civil possa desempenhar seu papel de influenciar as decisões do poder político e administrativo.

A diferenciação de papéis entre sociedade civil e Estado, assumindo a participação cidadã cada vez mais claramente a dimensão de controle social e de proposição, recoloca a discussão sobre o conflito entre representação e participação. A legitimidade dos agentes políticos eleitos pelo sufrágio universal, obedecidos os procedimentos de lisura e critérios justos de representatividade, é reforçada quando a sociedade civil participa de forma autolimitada, não os substituindo, mas exercendo o papel específico de tematizar as questões, formar consensos, fornecer parâmetros para decisão. Diante do quadro de deslegitimação e desprestígio social que enfrentam as instituições do sistema representativo, a participação cidadã pode contribuir para revitalizá-lo, não obstante verificarmos que essa contribuição é ainda muito reduzida. Da mesma forma, verifica-se que a participação cidadã ressente-se de dificuldades objetivas colocadas pela estrutura social e política que marginaliza os cidadãos e suas organizações, assim como de uma cultura política corporativa e imediatista que reduz sua eficácia política. Algumas experiências desenvolvidas com êxito na relação com o poder público carecem de uma reflexão mais profunda sobretudo tendo em vista possibilidades de ampliar a escala de atuação, reproduzindo-a enquanto políticas públicas através da sua assunção pelos aparelhos estatais. Para isso, do ponto de vista da sociedade civil, é necessário sistematizar essas experiências e submetê-las ao debate público com a participação dos diferentes atores. Do ponto de vista do poder público, a adoção de um novo processo de elaboração de políticas públicas que supera os limites burocrá- 
ticos e amplia seu espaço para além das fronteiras dos aparelhos estatais, tornando-as menos governamentais e mais públicas. Nesse sentido assume função estratégica a dimensão expressiva da participação, não só em termos de construção de identidades dos diversos grupos e movimentos sociais, mas do seu fortalecimento enquanto atores políticos que buscam agir em espaços públicos autônomos, construindo uma nova institucionalidade de que fala Vera Teles (1994).

A partir de exemplos identificados em vários países, o papel desenvolvido pelas organizações da sociedade civil no poder local demonstra a relevância política que essa esfera de poder vem obtendo nos últimos tempos, apesar do intenso processo de globalização. No espaço local repercutem os efeitos, sobretudo na área social, das políticas postas em prática por organismos intergovernamentais internacionais e das estratégias das grandes corporações multinacionais. Projetos de políticas compensatórias, com recursos desses organismos, realizam-se na esfera local, com a participação das autoridades locais e até com o envolvimento de organizações da sociedade civil (ONGs). Isto leva a concluir que a máxima dos ecologistas, "pensar global e agir local", torna-se incompleta. A globalização exige cada vez mais que as ações locais se articulem com ações globais. A temática do local, da cidade, está presente nos fóruns internacionais, exigindo também um "agir global".

A longa e penosa experiência de luta de muitos movimentos e organizaçōes em termos de reivindicaçōes e mobilizações durante períodos de governos autoritários em vários países, passa a ser utilizada agora numa perspectiva propositiva e crítica. Tentam, a partir de experiências localizadas de projetos em vários setores de atividades, oferecer alternativas de políticas públicas que possam capitalizar e generalizar os seus resultados. Em termos locais, os exemplos indicam uma crescente atuação política das organizações, numa relação mais dinâmica com o poder político, que vai desde a denúncia, controle de decisões, à proposição de políticas, à cogestão ou parceria em projetos concretos.

Tudo isso indica certo fortalecimento da sociedade civil local, em alguns países, através da articulação de redes temáticas e de uma atuação mais sistemática e coordenada, ocupando espaços nas esferas públicas institucionalizadas, ao tempo em que se criam espaços autônomos de interlocução. No entanto, a sociedade civil local enfrenta alguns proble- 
Sociedade Civil e seu Papel Político: O Local e o Global como Espaços de Participação Cidadã

mas e desafios. Cada vez mais as políticas são globalizadas e o âmbito de decisão da esfera local é reduzido, pois muitos campos de atividades são privatizados. As entidades enfrentam hoje o problema de sua própria sobrevivência financeira e a dependência aos recursos governamentais. Em relação a outros atores, os dados mostram certo refluxo na ação coletiva de vários movimentos, como o sindical, que enfrenta os duros efeitos da reestruturação produtiva, e o fortalecimento de outros, como os de jovens e de consumidores, na Europa, e os de camponeses, de gênero e ecológicos, na América Latina.

No Brasil, alguns atores retraem-se numa certa indefinição em ajustar-se aos novos cenários (Movimentos de Igreja, Movimento Operário), enquanto outros assumem o protagonismo, como é o caso do Movimento dos Trabalhadores Sem-Terra, dos Movimentos de Moradia. Com objetivo mais simbólico e expressivo, buscam maior visibilidade (Grito da Terra, Grito dos Excluídos). A ação no campo institucional tem-se ampliado utilizando-se de espaços criados. No campo da elaboração de algumas leis importantes, as organizações têm participado de forma intensa no processo de discussão, tanto em fóruns próprios como através de audiências públicas no parlamento (Lei de Assistência Social, Lei Agrária, Estatuto da Cidade, Lei de Saneamento, etc.).

Do ponto de vista organizacional, os dados indicam relativo fortalecimento da sociedade civil, com articulações horizontais através de fóruns e redes temáticas; as organizações verticalizadas, como as Centrais, perdem força, enquanto novas formas mais descentralizadas (Ação da Cidadania) em certo momento ganharam maior expressão social, sobretudo em setores médios da população e na mídia. As organizações de economia solidária - que têm o apoio de ONGs - voltadas para setores marginalizados (cooperativas, associações de pequenos produtores), ganham força diante do desemprego e do aumento da exclusão.

Experiências de participação no poder local em alguns municípios do país mostram, de um lado, a eficácia de inovações na gestão , a exemplo do "orçamento participativo", por outro lado, a vitalidade de iniciativas da sociedade civil, embora esparsas, que enfrentam uma cultura política tradicional e estilos mandonistas e populistas de gestão. Poucas organizações têm realizado essas experiências, mas os exemplos recolhidos indicam que a participação não se dá apenas por indução de aparelhos governamentais. 
O problema que se coloca é o da sua continuidade, em virtude das dificuldades encontradas no confronto com o poder e os resultados concretos alcançados em termos de mudanças de métodos.

O estudo de caso realizado em Valente (BA) aponta para essas possibilidades de participação da sociedade civil, quando forças sociais organizadas se articulam e obtém apoio em outros níveis (do regional ao internacional) com certo suporte técnico e financeiro. Mesmo assim, foram necessários mais de 15 anos de trabalho de base em cada comunidade, tendo enfrentado várias crises e desafios e contado com o apoio permanente de uma ONG da região - o MOC (Movimento de Organização Comunitária) - e recursos de agências internacionais. Esse trabalho de base permitiu a formação de um tecido associativo distribuído por todo o município e o protagonismo de uma das organizações que passou a liderar todo um processo de fortalecimento econômico, desdobrando-se, depois de algum tempo, em várias unidades produtivas (indústria, cooperativa de crédito, posto de vendas), realizando um trabalho de capacitação técnica e política com os pequenos produtores e cidadãos (Escola Família Agrícola, Rádio Comunitária). Do ponto de vista do empowerment econômico do segmento dos pequenos produtores e da região, os resultados foram significativos. No entanto, as implicações sociais de um crescimento econômico orientado pela lógica do mercado, sem considerar alguns parâmetros de equidade social, resultaram numa crise da organização hoje, que afeta as relações com as outras organizações, prejudicando um trabalho político que prometia mudanças. Sem muita clareza do papel crítico e transformador que poderiam exercer em relação ao poder local, as duas principais organizações locais entraram na competição eleitoral, cada uma optando por um candidato dos grupos dominantes locais, sem maior discussão com suas bases. No caso, por falta de uma estratégia bem definida e de uma avaliação coletiva, as organizações deixaram-se envolver no jogo do poder tradicional, tendo provocado uma séria crise que as levou à reavaliação e tentativa de redirecionamento de posições, ora em curso.

Várias experiências analisadas indicam as potencialidades da sociedade civil de contribuir para a efetivação da democratização do poder político, desde que os diferentes atores que a constituem tenham clareza das dimensões e limites que caracterizam a participação cidadã e utilizem os diversos mecanismos institucionais e sociopolíticos disponíveis para mudar 
as relações com o Estado e o mercado. Ao mesmo tempo, mostram a ambivalência desse processo. Para as organizações, torna-se importante criar uma base econômica própria para garantir sua autonomia e desenvolver experiências concretas que possam servir de base para construir alternativas de políticas públicas. Entretanto, ao inserirem nesse processo, correm o risco de assumir a lógica da competição e da acumulação, subestimando as potencialidades de construção de uma economia solidária. Em termos políticos, o desafio colocado é o de contribuir para a mudança da composição do poder e do estilo de fazer política, através de intenso trabalho de educação para a cidadania; da utilização dos espaços e esferas públicas; do exercício do controle social do poder; e, da proposição de alternativas para melhor aplicação dos recursos públicos.

$O$ conjunto diversificado de exemplos mostra-nos que as organizações da sociedade civil começam a desenvolver esse papel, sobretudo no espaço local, sem disporem ainda de força suficiente para mudar as relações, mas persistindo, com erros e acertos, na busca de caminhos e alternativas de uma efetiva participação cidadã.

\section{Nota}

'Texto extraído da Tese de Doutorado em Ciência Política, no Departamento de Ciência Política da Faculdade de Filosofia , Letras e Ciências Humanas, da USP, aprovada em 10.12.98, sob o título: Sociedade civil e participação cidadã no poder local, orientada pelo Prof. Dr. Lúcio Kowarick.

\section{Referências Bibliográficas}

BOBBIO, Norberto, O futuro da democracia: uma defesa das regras do jogo. 2" ediçááo. Rio de janeiro: Paz e Terra, 1986.

COSTA, Sérgio. Categoria política ou passe partout político normativo.Notas bibliográficas sobre o conceito de sociedade civil. BIB - Boletim Bibliográfico Brasileiro. Rio de Janeiro: ANPOCS, n. 43, 1997.

COHEN, Jean e ARATO, Andrew. Civil society and political theory. Cambridge:Mit Press, 1992. 
HABERMAS, Jurgen. Direito e Democracia: entre a factividade e a validade. 2 vs. Rio de Janeiro: Tempo Brasileiro, 1997.

PREZEWORSKI, Adam. The state and the citizen. Paper apresentado no Seminário sobre sociedade e reforma do Estado. São Paulo, 1998. TELLES, Vera da Silva. Sociedade Civil, Direitos e Espaços Públicos. In VILLABÔAS, Renata (org).Participação Popular nos Governos Locais. São Paulo: PÓLIS, 1994. 